Article

\title{
Friction-Induced Martensitic Transformation and Wear Properties of Stainless Steel under Dry and Wet Conditions
}

\author{
Yoon-Seok Lee *, Yuta Kondo and Mitsuhiro Okayasu \\ Graduate School of Natural Science and Technology, Okayama University, Okayama 700-8530, Japan; \\ p1yp1npg@s.okayama-u.ac.jp (Y.K.); mitsuhiro.okayasu@utoronto.ca (M.O.) \\ * Correspondence: y_lee@okayama-u.ac.jp; Tel.: +81-86-251-8026
}

Received: 17 April 2020; Accepted: 27 May 2020; Published: 3 June 2020

\begin{abstract}
The wear characteristics of SUS304 and SUS316 stainless steels were evaluated at the rotation speeds of $100 \mathrm{~m} / \mathrm{s}, 200 \mathrm{~m} / \mathrm{s}$, and $300 \mathrm{~m} / \mathrm{s}$ under dry and wet conditions. The transition of friction-induced martensite occurred in wear-affected regions of two materials, regardless of the wear test conditions. The specific wear rates $\left(W_{\mathrm{s}}\right)$ of both stainless steels increase with increasing rotation speeds, regardless of the circumstances. Moreover, $W_{\mathrm{S}}$ of SUS304 and SUS316, obtained under dry conditions, is significantly higher than that of SUS304 and SUS316 obtained under wet conditions, respectively. This is because that the water film on the wet ring can act as a liquid lubricant between the ring and the block during the tests. After the wear tests, the hardness changes of both SUS304 and SUS316 are much higher under dry conditions, compared to those under wet conditions.
\end{abstract}

Keywords: stainless steels; friction-induced transformation; lubricant; wear; martensite

\section{Introduction}

The austenitic stainless steel is widely used all over the world because of its mechanical properties such as high ductility, high heat resistance, and excellent corrosion resistance. However, the austenitic stainless steels are notorious for their poor friction and wear characteristics, despite of excellent corrosion resistance [1]. Particularly, the severe metallic wear could occur when in contact with other iron-based materials, demonstrating high metallurgical compatibility. For example, austenitic stainless steel tends to adhere onto common tool materials during the work processes, such as sliding, drilling, and cutting. This usually results in the degradation of surface quality and the acceleration of adhesive wear during the processes [2]. This is because metallurgically compatible metals have a substantial solubility of atoms of one of the metals in the lattice of the other. Consequently, they are frictionally incompatible, and frictionally incompatible metals show severe wear with strong adhesion [3].

Therefore, most of the machining operations on stainless steel alloys are carried out with water-based fluid due to the poor machinability [4]. Consequently, the wear tests have been conducted using stainless steel alloys under dry and water-lubricated conditions [4-6] because the wear tests are simple and the test conditions could be easily controlled, in comparison with real machining tests [6]. In this study, SUS304 (JIS) and SUS316 (JIS) were investigated as two representative austenitic stainless steels, and the wear characteristics of these alloys were evaluated under both dry and wet conditions in simulated lubricated and unlubricated contacts, respectively. Water was used in wet condition to obtain basic information of wear behavior in a water-lubricated condition.

Moreover, not only contact surfaces but also subsurface layers may be largely changed under the severe wear, leading to the changes in mechanical properties of these two alloys. Therefore, it is also necessary to investigate the microstructural evolution of subsurface layers and widen the range of 
application of the stainless steels [7]. In the subsurface layers of theses alloys, the transformation of $\gamma$-fcc to $\varepsilon$-hcp and $\alpha^{\prime}$-bcc phases can be generated owing to the friction stress, which is friction-induced martensitic transformation [8-10]. It should be noted that a martensitic structure could deteriorate corrosion resistance, leading to the stress corrosion cracking, although it may improve the surface hardness of materials.

A better understanding of the mechanism on a metallurgical basis, involved in the subsurface layer and lubricant effects, is required to improve their wear resistance because not much investigation, including the interpretation of wear behaviors on a metallurgical basis, has been reported. These investigations are considered to allow the effective forming and improve the life cycle of the parts in the industry.

\section{Experimental Procedure}

\subsection{Materials}

Two stainless steel rods (10 mm in diameter) made of SUS304 (Fe: bal., Cr: 20.3, Ni: 8.4, S: 0.2, Mn: 1.3, and Si: 0.3 mass\%) and SUS316 (Fe: bal., Mo: 2.2, Cr: 17.7, Ni: 10.0, S: 0.2, Mn: 1.6, and Si: 0.5 mass \%) were used as test blocks for the wear tests. Two different blocks were subjected to a solution treatment at $1373 \mathrm{~K}$ for $1 \mathrm{~h}$ followed by water quenching. In this study, a test ring $(150 \mathrm{~mm}$ in diameter and $15 \mathrm{~mm}$ in width) made of high speed steel (HSS, Fe: bal., V: 3.1, W: 1.1, Cr: 3.0, Mo: 3.1, Mn: 0.5, Si: 1.1, and C: 1.5 mass\%) was used as a counter material, which is often used in work processes such as drilling and cutting austenitic stainless steels [11-13].

In addition, the hardness of SUS304 and SUS316 test blocks was measured using a Vickers hardness tester (MVK-C, Akashi Co. Ltd., Tokyo, Japan) before and after the wear tests. The contact surfaces before the wear tests and longitudinal cross-sections after the wear tests were wet polished and buff polished using an $\mathrm{Al}_{2} \mathrm{O}_{3}$ powder and a colloidal $\mathrm{SiO}_{2}$ solution. Then, the hardness of the contact surfaces and longitudinal cross-sections were measured at loads of 9.8 and $0.245 \mathrm{~N}$, respectively. The hardness of all surfaces was measured for a holding time of $15 \mathrm{~s}$ and nine different points were measured for each block. The highest and lowest values were discarded, and the hardness of each block was determined using the average of the remaining seven values.

\subsection{Block-on-Ring Wear Test}

The block-on-ring wear-testing machine was used in this study. The wear tests were carried out at room temperature with a load of $7.3 \mathrm{~N}$ under dry and wet conditions. The bottom of the ring was submerged to soak the surface of the ring under wet conditions. Under both dry and wet conditions, each test was also carried out for $5 \mathrm{~h}$ at three different sliding speeds controlled by the HSS (C: 1.46, Si: 1.08, Mn: 0.49, P: 0.02, S: 0.01, Ni: 0.10, Cr: 3.02, Mo: 3.09, W: 1.11, V: 3.09, and Fe: bal. mass\%) ring with rotation speeds of 100,200 , and $300 \mathrm{rpm}$. All tests were performed three times under each condition. The weights of each block were $W_{1}$ and $W_{2}$ before and after the wear test. The wear weight loss $\left(W_{\text {loss }}\right)$ was calculated in $g$ using the following equation:

$$
W_{\text {loss }}=W_{2}-W_{1}
$$

$W_{\text {loss }}$ was converted into the volume loss $\left(V_{\text {loss }}\right)$ in $\mathrm{mm}^{3}$, by the following equation:

$$
V_{\text {loss }}=\frac{W_{\text {loss }}}{D_{\text {alloy }}}
$$

$D_{\text {alloy }}$ is the density of each alloy calculated using molecular weights. The screws were machined at the test blocks to be driven into the test rod in this study, which makes calculation of the volume of the 
blocks difficult. Therefore, $D_{\text {alloy }}$ was calculated using molecular weights in order to obtain precise density. Finally, the specific wear rate $\left(W_{s}\right)$ was obtained from the following equation:

$$
W_{\mathrm{s}}=\frac{V_{\text {loss }}}{F_{\mathrm{n}} L}
$$

where $F_{\mathrm{n}}$ is the normal load $(\mathrm{N})$ and $L$ is the sliding distance $(\mathrm{m})$.

The wear debris captured after the wear tests were examined to understand the wear behaviors and mechanisms using a scanning electron microscopy (SEM) combined with energy-dispersive spectroscopy (EDS). The wear mechanisms were also investigated by a morphological analysis of the wear tracks. In addition, some of the test blocks were sectioned parallel to the wear track (sliding direction) to observe the subsurface layer using a SEM-based electron back-scattered diffraction (EBSD) analysis. Then, the orientation data from the EBSD were analyzed using an Orientation Imaging Microscopy $\left(\mathrm{OIM}^{\mathrm{TM}}\right)$ analysis software (version 7.2, EDAX Inc., Mahwah, NJ, USA).

\section{Results and Discussion}

\subsection{Microstructures and Wear Characteristics}

Figure 1 shows the phase maps obtained using EBSD analysis of test blocks before the wear tests. Both materials consist of single $\gamma$-austenite phase in phase maps. The hardness values (mean \pm SD) of test blocks before the wear tests are $150 \pm 3.0 \mathrm{Hv}$ and $153 \pm 4.6 \mathrm{Hv}$ for SUS304 and SUS316, respectively. On the other hand, the hardness of HSS $(689 \mathrm{Hv})$ is significantly higher than any of the test blocks, while the hardness of the test blocks was almost the same value.
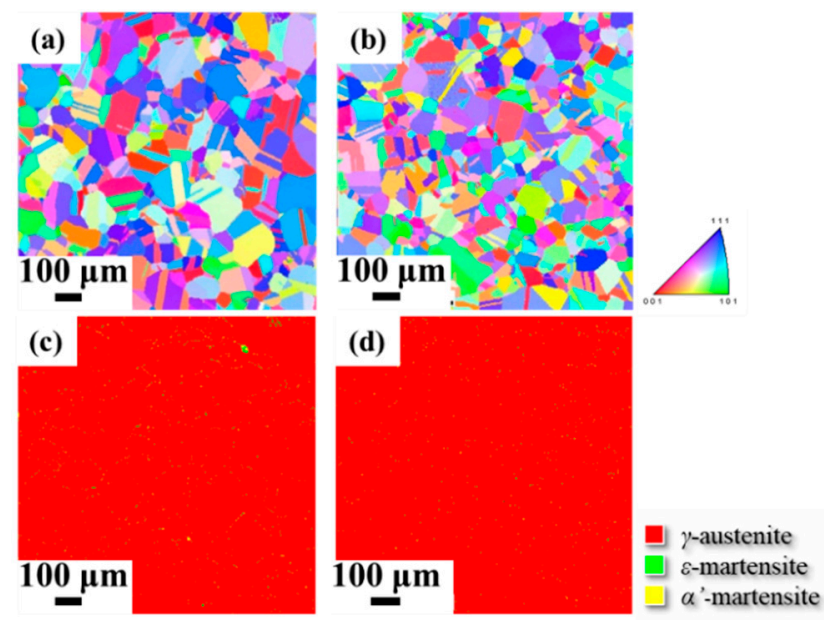

Figure 1. Electron back-scattered diffraction (EBSD) analysis of test blocks before wear test: inverse pole figure (IPF) maps of (a) SUS304 and (b) SUS316 and corresponding phase maps (PM) of (c) SUS304 and (d) SUS316.

$W_{\mathrm{s}}$ of the blocks, under dry and wet conditions, are represented in Figure 2. $W_{\mathrm{s}}$ of both materials increases with increasing rotation speeds, regardless of the circumstances. Moreover, $W_{\mathrm{S}}$ of SUS304 and SUS316 obtained from the tests under dry conditions, is significantly higher than that of SUS304 and SUS316 obtained from the tests under wet conditions, respectively. This is because that the water film on the wet ring can act as a liquid lubricant between the ring and the block during the tests. 


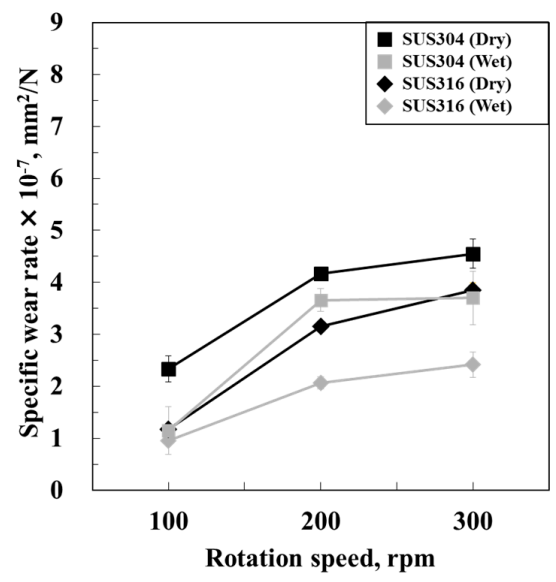

Figure 2. $W_{\mathrm{s}}$ of test blocks against HSS rings obtained from wear tests under dry and wet conditions.

Furthermore, the increases of $W_{\mathrm{s}}$ under wet conditions between 200 and $300 \mathrm{rpm}$ are lower than those under dry conditions, regardless of the block materials. There is particularly no sharp difference of $W_{\mathrm{s}}$ between 200 and $300 \mathrm{rpm}$ for SUS304 tested under wet conditions. This indicates that the effects of the water films, as a liquid lubricant, increase in more severe sliding conditions.

Figure 3 shows the wear tracks generated on the worn surfaces of SUS304 blocks resulted from the tests under dry and wet conditions. It is observed that the plastic deformation of the wear tracks becomes more severe with increasing rotation speed, regardless of the circumstances. The severe plastic deformation with smeared surfaces occurs owing to the strong adhesion between the ring and the blocks during the tests. Therefore, a severe surface traction is exerted towards the direction of the ring rotation by normal and tangential loads at the actual area of asperity contact $\left(A_{\mathrm{r}}\right)$ [14]. Consequently, the wear track generated at $300 \mathrm{rpm}$ shows the most severe plastic deformation because the tangential load increases with increasing rotation speed due to the strong adhesion. Furthermore, the wear track (Figure 3c) also shows delamination, which indicates delamination wear. The strong adhesion is a prerequisite for the delamination. Therefore, it is considered that the delamination occurs owing to the strong adhesion at the metal-to-metal contacts between the ring and block, leading to the strong plastic shear deformation in the subsurface of the block [14-16].
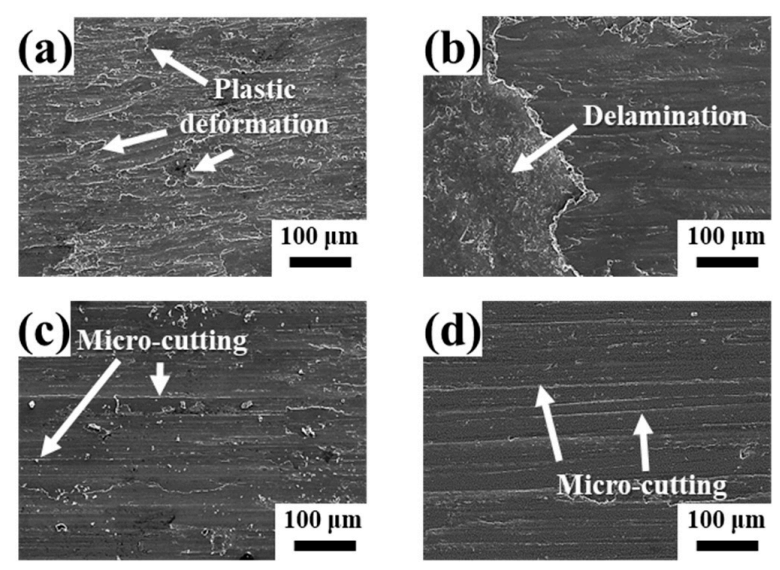

Figure 3. SEM micrographs of wear tracks on SUS304 blocks at rotation speeds of (a) $100 \mathrm{rpm}$ and (b) $300 \mathrm{rpm}$, obtained from wear tests under dry conditions, and rotation speeds of (c) $100 \mathrm{rpm}$ and (d) $300 \mathrm{rpm}$, obtained from wear tests under wet conditions.

As shown in Figure 3d-f, the wear tracks of SUS304 blocks are partially characterized by a small extent of deformation and the uniform grooves, which indicates the abrasive wear. These wear tracks, formed under wet conditions, show a significantly smaller extent of surface deformation than those 
formed under dry conditions. This is because that the water film can act as a liquid lubricant between the ring and block, as mentioned above. Consequently, the plastic deformation significantly reduces under wet conditions since the water lubricant film reduces metal-to-metal contacts, leading to decrease in adhesion.

The frictional coefficient also increase when the wear test is conducted under dry conditions, as compared to under wet conditions [17-19]. In a fluid-lubricated system, the ratio between the thickness of the lubricant film and the asperity height of the surfaces $(\lambda)$ determines the lubricant effects $[20,21]$. When the water film on the ring acts as a liquid lubricant during sliding, the thickness of the water films can be larger than the asperity height, in this study. When $\lambda$ is above approximately 1 for metals, then the asperities on the opposing surfaces do not come into contact with one another and the $W_{\mathrm{s}}$ will be reduced. This is because $W_{\mathrm{s}}$ depends on $A_{\mathrm{r}}$ that is, the total sizes of the asperity junctions. It should be noted that $A_{\mathrm{r}}$ is one of the most important factors for determining the extent of the delamination wear because the average size of each delaminated debris can be assumed to be proportional to $A_{\mathrm{r}}$.

On the other hand, Figure 4 represents the wear tracks generated on the SUS316 blocks under dry and wet conditions. The wear tracks of SUS316 also show larger plastic deformation under dry conditions, compared to wet conditions, which is similar to the findings of SUS304. Moreover, the wear tracks tested under dry conditions become more severe with increasing rotation speed. The wear tracks tested under wet conditions have a large number of regular grooves and micro-cutting, which are generally observed in mild abrasive wear. This is similar to $W_{\mathrm{s}}$ of SUS316 tested under wet conditions, which shows the lowest values, regardless of rotation speeds.
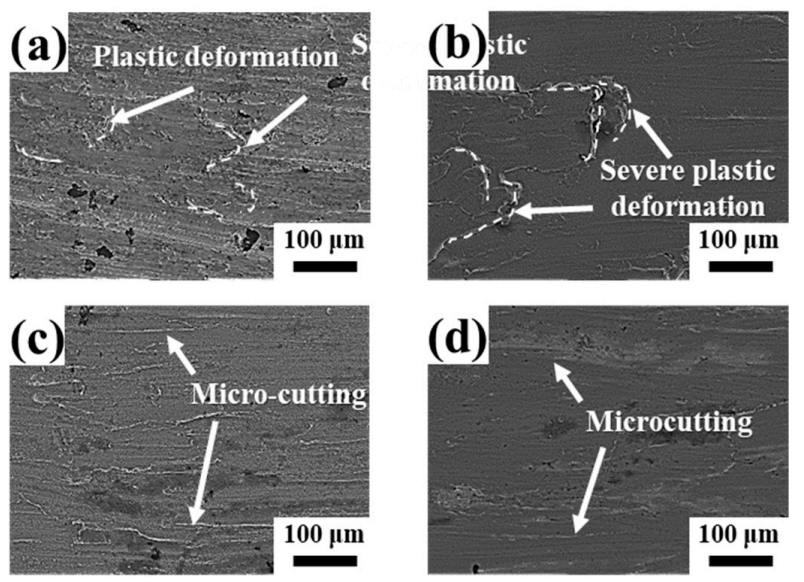

Figure 4. SEM micrographs of wear tracks on SUS316 blocks at rotation speeds of (a) $100 \mathrm{rpm}$ and (b) $300 \mathrm{rpm}$, obtained from wear tests under dry conditions, and rotation speeds of (c) $100 \mathrm{rpm}$ and (d) $300 \mathrm{rpm}$, obtained from wear tests under wet conditions.

The morphological analysis of the wear debris collected from SUS304 and SUS316, tested at a rotation speed of $300 \mathrm{rpm}$, is shown in Figure 5. Three different debris were observed: very fine debris, plate-like debris, and blocky debris. Particularly, a large amount of the plate-like debris (Figure 5a-d), indicating the delamination wear [22-24], were generated. The sizes of the plate like-debris (delaminated debris) are strong evidence to speculate the extent of plastic shear deformation accumulated in subsurface layers. The sizes of the plate-like debris are larger under dry conditions $(10.5 \mu \mathrm{m})$ than under wet conditions, as shown in Figure 5. In the theory of delamination, first proposed by Suh [22] and successively discussed by numerous authors [25,26], the contacting asperities experience an incremental plastic deformation during sliding, which accumulates during repeated contacts. At a critical level of accumulated strain, the subsurface cracks are nucleated below the wear track. When the crack becomes sufficiently large, it fractures to yield large plate-like debris. According to the results, both SUS304 and SUS316 blocks have more severe delamination wear under dry conditions, compared 
to wet conditions. The EDS analysis was also carried out to analyze the wear debris, as represented in Figure 5e,f. Strong peaks of chrome and nickel are detected, which indicates that they are from the test blocks rather than from the ring.
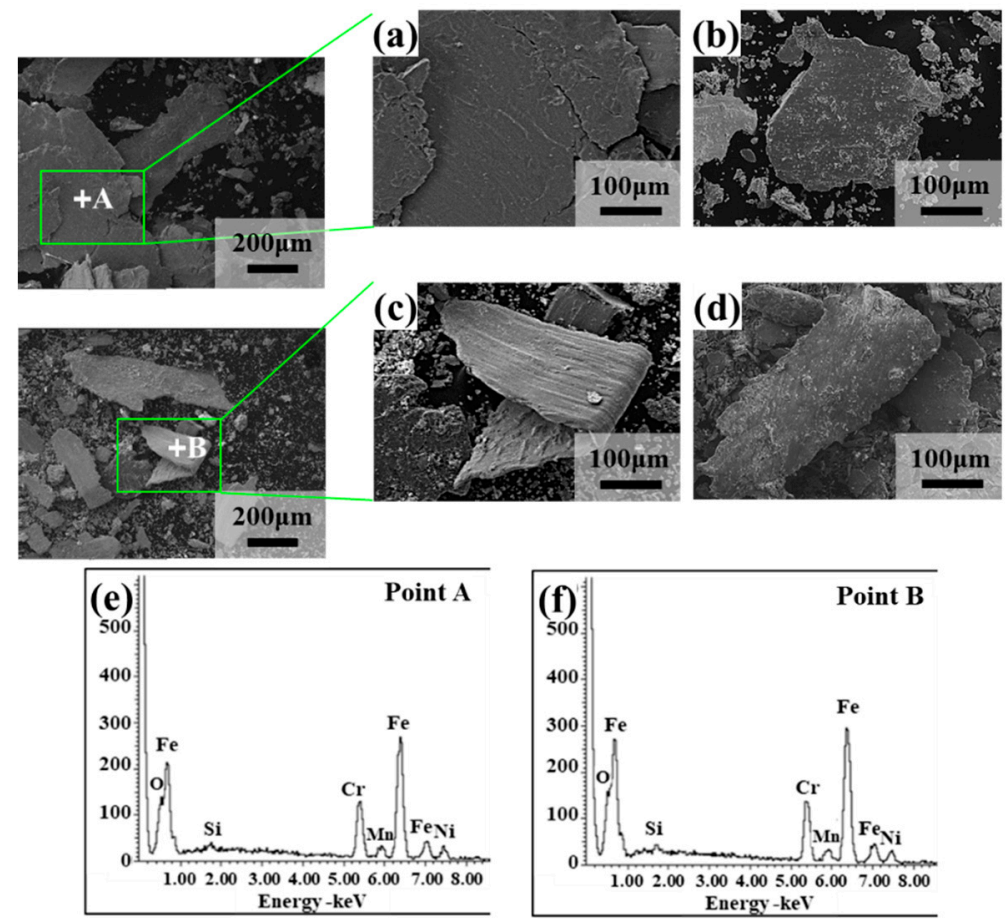

Figure 5. Morphologies of debris collected at the end of wear tests and corresponding EDS analysis; SEM micrographs of plate-like debris from SUS304 obtained under (a) dry and (b) wet conditions, SUS316 under (c) dry and (d) wet conditions, and EDS patterns for (e) point A and (f) point B.

\subsection{Hardness Evolution of Subsurface}

The hardness as a function of distance from the surface is shown in Figure 6. For SUS304 and SUS316, the hardness respectively decreases to the bulk layer over around $170 \mu \mathrm{m}$ and $100 \mu \mathrm{m}$ in depth and then becomes constant in the steady state region under dry and wet conditions. On the other hand, the surface is hardened up to $500 \mathrm{Hv}$ for SUS304 and up to $450 \mathrm{Hv}$ for SUS316, from the origin surface at $300 \mathrm{rpm}$ under dry conditions. Based on the results, the wear-affected region becomes hard by severe plastic flow, which results from the normal and tangential loads transmitting through the contact points. Moreover, the hardness changes of both materials are significantly higher at the same rotation speed under dry conditions, compared to that under wet conditions. This is also because that water lubricant film leads to the reduction of both $A_{\mathrm{r}}$ and adhesion during the wear tests.
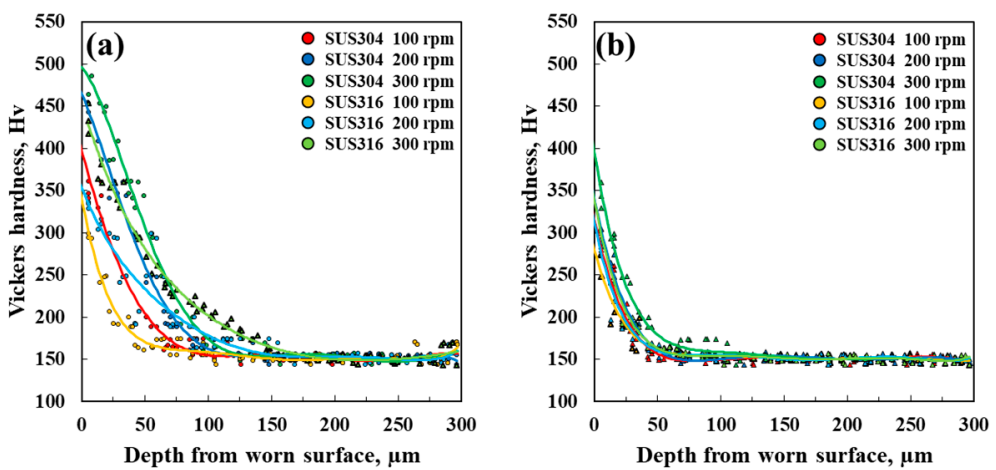

Figure 6. Variation of hardness as a function of distance from worn surfaces of test blocks after wear tests under (a) dry and (b) wet conditions. 
The hardness changes of SUS304 and SUS316 increase with increasing rotation speed and the results shows larger increases under dry conditions, as shown in Figure 6a. It can be also explained by the plastic shear deformation at the subsurface layer that increases with increasing rotation speed, which leads to high strain-hardening rates in subsurface. Particularly, larger increases are observed under dry conditions, regardless of rotation speed, since transmitted tangential loads significantly increase via strong adhesion. On the other hand, the hardness changes of SUS304 and SUS316 are not so large under wet conditions, although the hardness also increases with increasing rotation speed. This is because that the effects of the rotation speeds on subsurface layers are smaller under wet conditions, owing to the smaller adhesion and strain hardening.

\subsection{Phase Transformation Behavior}

EBSD analysis was carried out to investigate the evolution of subsurface layer of the blocks. SUS304 consists of single $\gamma$ phase before the wear tests (Figure 1). Both $\varepsilon$ and $\alpha^{\prime}$ phases are observed below the worn surfaces of the blocks tested under any circumstances. It is believed that the friction stress at the contact surface generate the transformation of $\gamma$ to $\varepsilon / \alpha^{\prime}$ martensite, which is friction-induced martensite (FIM).

Figure 7 shows that the amount of martensite slightly increases with increasing rotation speed. The strong adhesion, leading to a high frictional coefficient, can cause high transmitted loads. Consequently, strain accumulation is accelerated with severe subsurface deformation in the blocks. Thus, the amount of generated martensite increases with increasing rotation speed. Particularly, the contacting surfaces, which consist of same chemical composition, demonstrate high metallurgical compatibility [2]. Most of the strong adhesion is considered to come from this high metallurgical compatibility as aforementioned above. In conclusion, it is believed that increase in amount of martensitic layer results from their same main chemical composition (Fe).

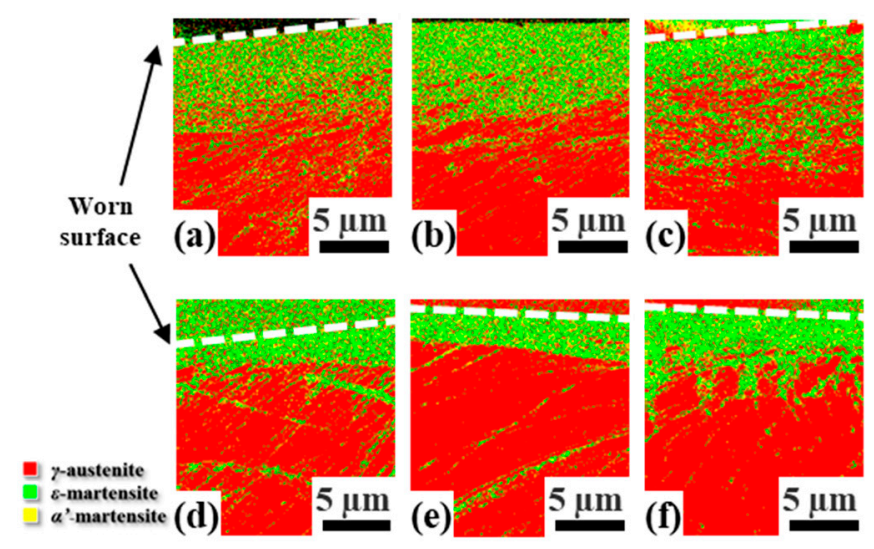

Figure 7. EBSD analysis of cross-sectioned SUS304 blocks after wear tests: phase maps (PM) of blocks at rotation speeds of (a) 100, (b) 200, and (c) $300 \mathrm{rpm}$ obtained from tests under dry conditions and rotation speeds of (d) 100, (e) 200, and (f) $300 \mathrm{rpm}$ obtained from tests under wet conditions.

Figure 8 shows depths of martensite layers from worn surfaces as a function of rotation speeds after the wear tests. The depths of martensite layers in both SUS304 and SUS316 is significantly large under dry conditions, compared to wet conditions. Moreover, there is no sharp difference between SUS304 and SUS316 under the same circumstances, except a difference of $100 \mathrm{rpm}$ under dry conditions. High stacking fault energy (SFE) is related to high austenite stability, retarding nucleation of martensite [27]. Moreover, the SFE value of austenitic stainless steels increases with increasing molybdenum content. Consequently, the existence of molybdenum in SUS316 could retard FIM transformation at a low rotation speed of $100 \mathrm{rpm}$. At $200 \mathrm{rpm}$ and $300 \mathrm{rpm}$ under dry conditions, it is believed that the amount of delaminated surfaces is too large to present the effects of Mo, owing to the severe wear. 


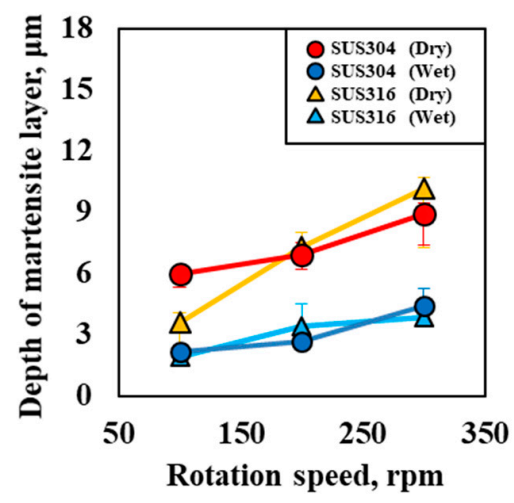

Figure 8. Depth distribution of martensitic transformations as a function of rotation speeds for SUS304 and SUS316 blocks under dry and wet conditions.

As aforementioned above, stainless steel alloys can suffer the severe metallic wear, such as delamination wear, when in contact with other metals. In particular, when the counter material consists of a high ratio of $\mathrm{Fe}$, strong adhesion occurs, leading to strong subsurface shear deformation with martensitic transformation. A martensitic structure could deteriorate corrosion resistance, which leads to the stress corrosion cracking. Therefore, various water-based liquid lubricants are often used in the work processes, drilling and cutting austenitic stainless steels. The wear characteristics, adhesion of contacting surfaces, and subsurface deformations under different contact conditions could provide basic understanding for the work process.

\section{Summary}

The wear characteristics of two different stainless steels were evaluated under dry and wet conditions. Among the key findings are the following:

1. $W_{\mathrm{s}}$ of two materials increases with increasing rotation speeds, regardless of the circumstances.

$W_{\mathrm{S}}$ of SUS304 and SUS316 obtained from the tests under dry conditions is higher than that of SUS304 and SUS316 obtained from the tests under wet conditions, respectively. This is because the water film on the wet ring can act as a liquid lubricant.

2. The plastic deformation of the wear tracks becomes more severe with increasing rotation speed, regardless of the circumstances. The severe plastic deformation resluts from the strong adhesion between the ring and the blocks. Moreover, the wear tracks, formed under wet conditions, show a significantly smaller extent of surface deformation than those formed under dry conditions.

3. A large amount of the plate-like debris is observed after the wear tests. According to the results, both materials have more severe delamination wear under dry conditions, compared to wet conditions.

4. In both materials, the hardness decreases to the bulk layer under dry and wet conditions, respectively. The hardness changes of two materials are higher at the same rotation speed under dry conditions, compared to those under wet conditions. This is because the water lubricant film leads to the reduction of $A_{\mathrm{r}}$ and adhesion.

The thicknesses of martensitic structures are larger in SUS304 at low rotation speed under dry condition. It is considered that high SFE, resulting from the existence of molybdenum, could retard FIM transformation for SUS316.

Author Contributions: Conceptualization, Y.-S.L.; methodology, Y.-S.L. and Y.K.; formal analysis, Y.-S.L. and Y.K.; investigation, Y.-S.L. and Y.K.; resources, M.O.; data curation, Y.K.; writing-original draft preparation, Y.-S.L.; writing-review and editing, Y.-S.L. and M.O.; visualization, Y.K.; supervision, Y.-S.L.; project administration, M.O. All authors have read and agreed to the published version of the manuscript.

Funding: This research received no external funding.

Conflicts of Interest: The authors declare no conflict of interest. 


\section{References}

1. Sun, Y.; Bell, T. Dry sliding wear resistance of low temperature plasma carburised austenitic stainless steel. Wear 2002, 253, 689-693. [CrossRef]

2. Wei, X.-C.; Hua, M.; Xue, Z.; Gao, Z.; Li, J. Evolution of friction-induced microstructure of SUS 304 meta-stable austenitic stainless steel and its influence on wear behavior. Wear 2009, 267, 1386-1392. [CrossRef]

3. Rabinowicz, E. Friction and Wear of Materials, 2nd ed.; Wiley: New York, NY, USA, 1995.

4. Junior, A.B.; Diniz, A.E.; Filho, F.T. Tool wear and tool life in end milling of 15-5 PH stainless steel under different cooling and lubrication conditions. Int. J. Adv. Manuf. Technol. 2009, 43, 756-764. [CrossRef]

5. Jia, J.; Zhou, H.; Gao, S.; Chen, J. A comparative investigation of the friction and wear behavior of polyimide composites under dry sliding and water-lubricated condition. Mater. Sci. Eng. A 2003, 356, 48-53. [CrossRef]

6. Xingzhong, Z.; Jiajun, L.; Baoliang, Z.; Hezhou, M.; Zhenbi, L. Wear behavior of Si3N4 ceramic cutting tool material against stainless steel in dry and water-lubricated conditions. Ceram. Int. 1999, 25, 309-315. [CrossRef]

7. Lee, Y.-S.; Ishikawa, K.; Okayasu, M. Influence of Strain Induced Martensite Formation of Austenitic Stainless Steel on Wear Properties. Met. Mater. Int. 2018, 25, 705-712. [CrossRef]

8. McEvily, A.J.; Velazquez, J.L.G. Fatigue crack tip deformation. Metall. Trans. A 1992, 23, 2211-2221. [CrossRef]

9. Fiedler, H.C. The effect of deformation on the martensitic transformation in austenitic stainless steels. Trans. ASM 1955, 47, 267-290.

10. Choi, J.-Y.; Jin, W. Strain induced martensite formation and its effect on strain hardening behavior in the cold drawn 304 austenitic stainless steels. Scr. Mater. 1997, 36, 99-104. [CrossRef]

11. Çiçek, A.; Kıvak, T.; Uygur, I.; Ekici, E.; Turgut, Y. Performance of cryogenically treated M35 HSS drills in drilling of austenitic stainless steels. Int. J. Adv. Manuf. Technol. 2011, 60, 65-73. [CrossRef]

12. Belan, M.; Michalik, P. The durability and wear of coated mills from HSS-PM in stainless steel cutting without cutting fluid. In Proceedings of the 23rd DAAAM International Symposium on Intelligent Manufacturing and Automation, Zadar, Croatia, 24-27 October 2012.

13. Çiçek, A.; Uygur, I.; Kıvak, T.; Ozbek, N.A. Machinability of AISI 316 Austenitic Stainless Steel with Cryogenically Treated M35 High-Speed Steel Twist Drills. J. Manuf. Sci. Eng. 2012, 134, 061003. [CrossRef]

14. Lee, Y.-S.; Niinomi, M.; Nakai, M.; Narita, K.; Cho, K. Predominant factor determining wear properties of $\beta$-type and $(\alpha+\beta)$-type titanium alloys in metal-to-metal contact for biomedical applications. J. Mech. Behav. Biomed. Mater. 2015, 41, 208-220. [CrossRef] [PubMed]

15. Lee, Y.-S.; Niinomi, M.; Nakai, M.; Narita, K.; Cho, K. Differences in Wear Behaviors at Sliding Contacts for $\beta$-Type and $(\alpha+\beta)$-Type Titanium Alloys in Ringer's Solution and Air. Mater. Trans. 2015, 56, 317-326. [CrossRef]

16. Lee, Y.-S.; Niinomi, M.; Nakai, M.; Narita, K.; Cho, K.; Liu, H. Wear transition of solid-solution-strengthened $\mathrm{Ti}-29 \mathrm{Nb}-13 \mathrm{Ta}-4.6 \mathrm{Zr}$ alloys by interstitial oxygen for biomedical applications. J. Mech. Behav. Biomed. Mater. 2015, 51, 398-408. [CrossRef] [PubMed]

17. Sioshansi, P. Wear improvement of surgical titanium alloys by ion implantation. J. Vac. Sci. Technol. A 1985, 3, 2670-2674. [CrossRef]

18. Joyce, T.J.; Unsworth, A. The wear of artificial finger joints using different lubricants in a new finger wear simulator. Wear 2001, 250, 199-205. [CrossRef]

19. Kazerooni, N.A.; Bahrololoom, M.; Shariat, M.; Mahzoon, F.; Jozaghi, T. Effect of Ringer's Solution on Wear and Friction of Stainless Steel 316L after Plasma Electrolytic Nitrocarburising at Low Voltages. J. Mater. Sci. Technol. 2011, 27, 906-912. [CrossRef]

20. Hutchings, I. Tribology: Friction and wear of engineering materials. Mater. Des. 1992, 13, 187. [CrossRef]

21. Czichos, H.; Habig, K.H. Mixed lubrication and lubricated wear. In Proc. 11th Leeds-Lyon Symp. on Tribology; Butterworths: London, UK, 1985.

22. Suh, N.P. The delamination theory of wear. Wear 1977, 44, 1-16. [CrossRef]

23. Wilson, S.; Alpas, A. Thermal effects on mild wear transitions in dry sliding of an aluminum alloy. Wear 1999, 225, 440-449. [CrossRef]

24. Zhang, J.; Alpas, A. Wear regimes and transitions in $\mathrm{Al} 2 \mathrm{O} 3$ particulate-reinforced aluminum alloys. Mater. Sci. Eng. A 1993, 161, 273-284. [CrossRef] 
25. Molinari, A.; Straffelini, G.; Tesi, B.; Bacci, T. Dry sliding wear mechanisms of the Ti6Al4V alloy. Wear 1997, 208, 105-112. [CrossRef]

26. Straffelini, G.; Molinari, A. Dry sliding wear of Ti-6Al-4V alloy as influenced by the counterface and sliding conditions. Wear 1999, 236, 328-338. [CrossRef]

27. Talonen, J.; Hänninen, H. Formation of shear bands and strain-induced martensite during plastic deformation of metastable austenitic stainless steels. Acta Mater. 2007, 55, 6108-6118. [CrossRef]

(C) 2020 by the authors. Licensee MDPI, Basel, Switzerland. This article is an open access article distributed under the terms and conditions of the Creative Commons Attribution (CC BY) license (http://creativecommons.org/licenses/by/4.0/). 